\title{
CFD ANALYSIS OF THERMAL AND FLOW PHYSICS IN BUILDINGS UTILIZING SMART GLAZING FOR MITIGATION OF SOLAR GAIN
}

\author{
Yona Samuel $^{1 *}$, Thomas Confrey ${ }^{1}$, Dean Callaghan ${ }^{1}$, Nigel Kent ${ }^{1}$, Cathal Nolan ${ }^{1}$ \\ ${ }^{1}$ Department of Aerospace, Mechanical and Electronic Engineering, \\ Institute of Technology Carlow, Ireland
}

\begin{abstract}
Modern architectural design trends unanimously include glass facades in the construction of large buildings. An undesirable consequence of this design approach is solar gain which leads to uncontrollable space heating and an increase in interior air temperatures leading to poor thermal comfort of occupants. As glass is highly transparent in the visible and shortwave spectra, solar radiation passes easily to the building interior where the energy is absorbed by objects and surfaces and retained within the enclosed domain of the interior space. Active interventions such as air conditioning, solar control glass coatings, automated mechanical louvers, blinds, curtains etc are required to alleviate the effects of solar gain. These common methods have alarming disadvantages through poor energy efficiency, high costs, environmental impacts and poor aesthetic qualities. Switchable windows offer a contemporary smart controlled technological solution with very low electrical consumption and controlled levels of transparency/opacity through the activation of an electrically conductive inter layer between two glass panes. The current study investigates the utilization of smart glazing/switchable windows to combat the undesirable psychological and physiological effects of solar gain. Full scale CFD simulations were employed in order to investigate the fundamental thermal and flow physics in a large open space, typical of public and commercial buildings. A number of cases for varying solar loads incident on smart glazing were investigated. Results demonstrated the effectiveness of utilizing smart glazing in maintaining desirable ambient temperatures in the open spaces contributing to improved energy efficiency and occupant thermal comfort.
\end{abstract}

KEYWORDS: CFD, Simulation, Smart Glazing, Buildings, Energy Efficiency

\section{INTRODUCTION}

Large glazing surface areas such as in building facades are susceptible to allowing living spaces to overheat due to solar gain during hot days. The study of thermal comfort in buildings with the use of smart switchable windows tends to be a popular and essential direction for engineering investigation and development worldwide. Ninety percent of our lives is spent indoors, thus the study of thermal comfort of occupants has become of vital importance. Thermal comfort is a state of mind that articulates pleasure with the thermal environment. Feeling comfortable in a living space or workplace is proven to have a direct impact on the moods of the inhabitants and boosts mental health and work productivity [1]. During hot weather conditions, current glazing/windows are susceptible to allowing overheating of the building interior. Studies have shown that smart switchable windows are an efficient way of creating a thermally comfortable living environment in buildings. Smart glazing can modify their optical and thermal properties to adapt to the environmental conditions to avoid undesired energy/solar gain and light glare [2], [3]. Smart switchable glazing is well identified for improving the interior building conditions by creating a variation of daylight utilisation, reducing glare discomfort, creating a thermally comfortable environment, and maximising the privacy.

*Corresponding Author: thomas.confrey@itcarlow.ie 
These aspects are being driven by intuition to improve energy usage and carbon emissions through the reduction of cooling, heating, and lighting energies. This paper will investigate the utilization of smart glass switchable windows to combat the undesirable psychological and physiological effects of solar gain. Full-scale CFD simulations will be adopted to investigate the fundamental thermal and flow physics interactions in the building.

The analysis extends from the fundamental scenario of natural convection in a differentially heated cavity applied to three cases in a building HVAC system which include, Case A: No ventilation in the room, Case B: Passive ventilation and Case C: Air conditioning system. The transient CFD analysis will incorporate a study of natural convection in the room space as the window is exposed to two different constant temperature boundary conditions of $60^{\circ} \mathrm{C}$ and $30^{\circ} \mathrm{C}$ on the glazing for over a period of one hour. The chosen glazing temperatures are representative of intense/moderate solar radiation weather conditions on smart windows in Ireland based on experimentally recorded data on a switchable glazing test cell in an opaque state [4].

\subsection{Thermal Comfort in Buildings}

Several studies have been carried out in the field of the thermal comfort conditions of buildings using smart and normal standard glass windows. These were carried out in different housing cases such as inoffice rooms, classrooms, occupant's living spaces, etc. Most of the authors in the literature mainly focused on the thermal comfort of occupants by exploring more on a standard of thermal comfort of occupants published by an authorised organisation [3]. Some of the studies include laboratory investigation, where an actual smart glazing window is compared to a plane standard glazing window in terms of their heat emissivity into building interiors [5]. On the other hand, Computational Fluid Dynamics (CFD) was also another method that literature has shown how the thermal comfort of occupants was investigated [6], [7]. This paper looks at how building facades installed with smart glazing windows exposed to the direction of the sun that allows the transition of heat into the building interior creates a comfortable living/working environment.

Sabry et al. [8] performed a study on the thermal performance of a solar cell water flow type of smart window using a validated CFD model. To understand the thermal performance of the window, they aimed to study how the smart window type is absorbing heat and radiation from the sunlight. It led them to study the characteristics of the heat transfer through the temperature gradient and the airflow to the room as window temperatures change from low to higher values. By changing the boundary condition on the window type and considering the different versions of the solar cell and water type window, it helped them in acknowledging the best version of the window type and the ones that would be worth further studies by looking at their efficiencies. Their study was on the thermal characteristics of a window specified temperature effect following the size of the room. Their studies showed that different versions of the window type have different heat transfer behaviour and the lower the heat transfer from the window through the interior of the room, the higher the efficiency of the window. Therefore, they concluded that simulating the characteristics of the interior airflow and the difference in the temperature gradient helps to determine the performance of the different types of installed windows thus discovering the benefits of the smart windows. Javad and Navid performed a CFD study on the thermal comfort of a stratified indoor environment in displacement ventilation an adaptive climate building with smart windows [7]. Their study showed that a $0.1 \mathrm{~m} / \mathrm{s}$ airflow generated through natural convection during a hot day with a prismatic heat source could cause discomfort of occupants. They concluded that the temperature difference between the floor and ceiling would be larger than $5^{\circ} \mathrm{C}$. However, lower heat transfer rate into the room through the studied smart windows compared to that through a prismatic heat source, requires the supply velocity of $0.1 \mathrm{~m} / \mathrm{s}$ at the inlet to meet the occupant thermal comfort. The current analysis will distinguish the usage of a smart switchable glazing window that changes the optical state from clear to opaque utilizing two different equivalent constant temperature gradients. 


\section{METHODOLOGY}

The investigation will analyze the thermal comfort of occupants in a building with the use of smart switchable windows using the computational fluid dynamics (CFD) software Ansys Fluent. The Dargan building at the Institute of Technology Carlow was used as a case study to investigate the thermal comfort of occupants for various ventilation scenarios. The method of utilising smart glazing windows to create a thermally comfortable environment for an office occupant to decreases the solar heat gain and to eliminate the discomfort created by the light glare is recommended in previous studies [6], [7]. The analysis focuses on one room of the building and will develop a 2D CFD model that analyses the effect of controllable glass on the thermal comfort of occupants with various higher temperatures exposed on the window. A site visit to the building was carried out to take measurements of the size of the window and the office. The measurements were used to construct a two-dimensional CFD geometry to compass the study. As described in Fig. 1, the office measurement of $7.2 \mathrm{~m}$ of length and a height of $3.6 \mathrm{~m}$ was used to generate an interior $2 \mathrm{D}$ plane to facilitate the simulation of the thermal comfort analysis. Different scenarios of room ventilation were considered for the study to verify the most appropriate conditions for the room.
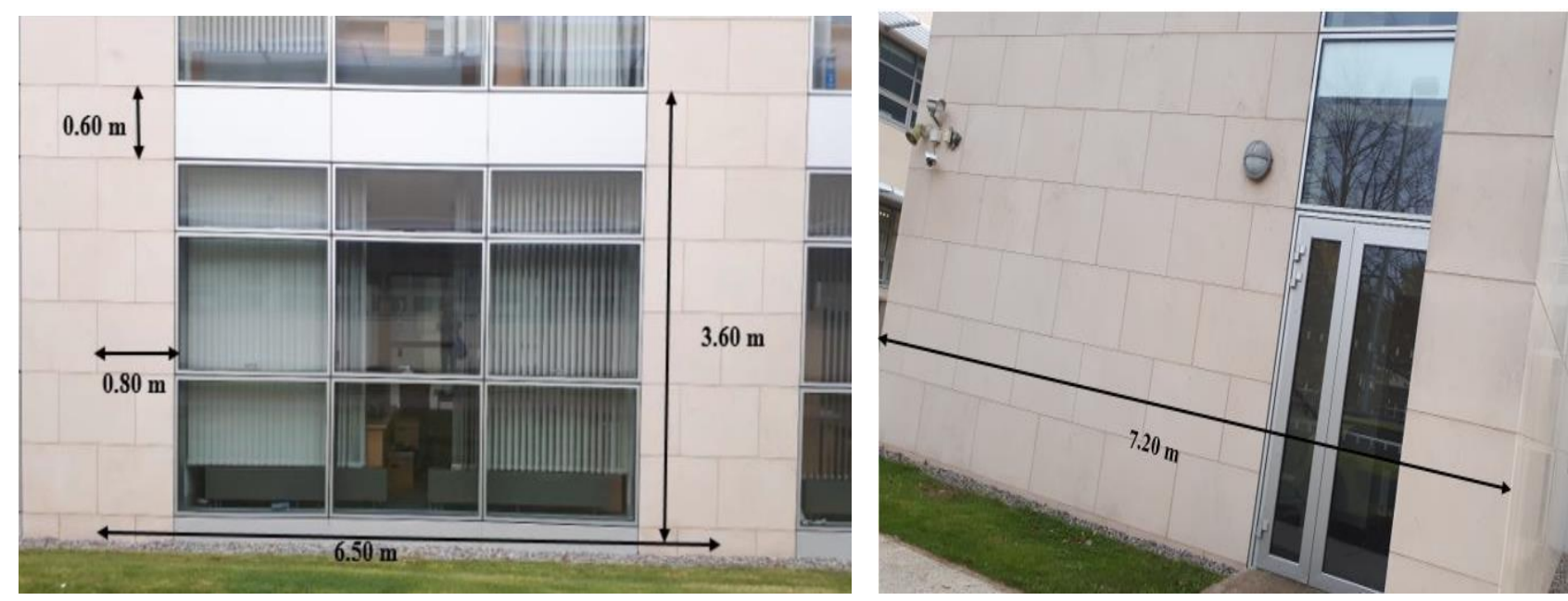

Fig. 1 The Dargan centre case study office building dimensions. 


\subsection{CFD Pre-processing}

The geometry was meshed using a structured mesh producing a fine mesh near the walls of the geometry for better modelling of heat transfer and airflow across the boundary layers of the room interior. The center of the plane was kept at a coarser mesh as a result of airflow being more stagnant. A mesh sensitivity analysis was used so that an ideal mesh sizing could be obtained to give a better convergence of the simulations. Boundary conditions were applied to the geometry to define the geometry in terms of their properties. As described in Fig. 2 the window was defined as the heat source in the room using a constant temperature boundary condition of $30^{\circ} \mathrm{C}$ and $60^{\circ} \mathrm{C}$, which correspond to typical smart glazing temperatures for moderate and intense solar loads in opaque states [4]. The front envelope wall was maintained at a constant room temperature of $20^{\circ} \mathrm{C}$. The roof and floor walls were identified as adiabatic walls, treated as a zero-heat flux boundary condition walls [9]. The ceiling geometry was modified to include a passive vent or an air conditioning inlet for cases B and $\mathrm{C}$. The boundary condition adaptation permits specification of the three cases of study (i.e. Case A: No ventilation, Case B: Passive Ventilation and Case C: Air conditioning).
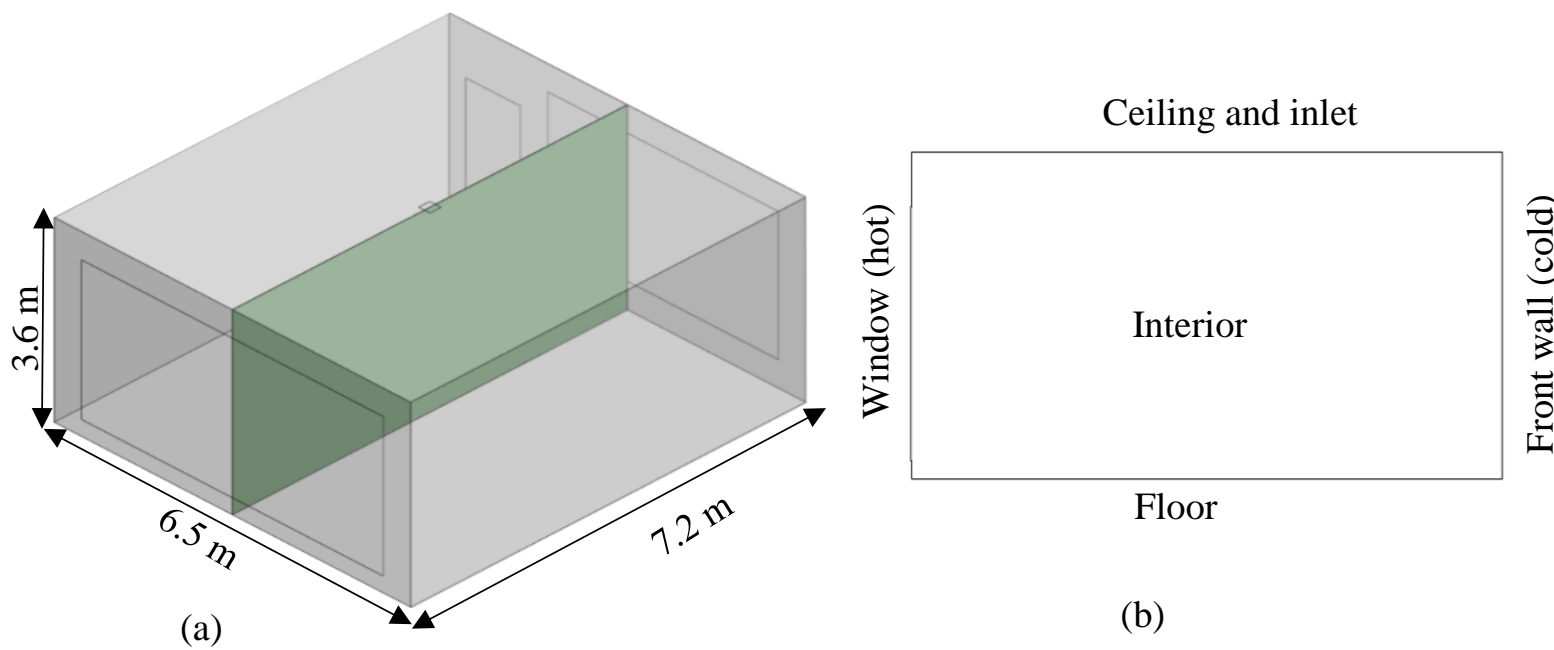

Fig. 2 Schematic of studied room (a) full-scale 3D of the room showing the plane of interest (b) 2D sketch of the plane of interest identifying the boundary conditions. 


\subsection{CFD Model Settings}

A transient simulation was used to predict the internal temperature and airflow with each case simulated for a time step of 0.01 seconds for a duration of 3600 seconds. It was observed that the window remains at a constant temperature for each case during the simulation. Since the glass window/wall absorbs and transmits heat, the room temperature increases; thus due to natural convection and buoyancy air begins to circulate inside the room. The Boussinesq approximation is a simple way of simulating natural convection without performing density calculations in the Navier-Stokes equation [10]. However, the Boussinesq approximation allows for a very small temperature difference in the ambient regions of the room. This study mainly considered higher temperature differences between the glazing and average room temperature. Therefore, a piecewise-linear interpolation method was chosen to suit the condition and the aim of the article to use high-temperature differences that cause variation in density of the air. The input data for the air density respected the temperature range of interest as presented in Table 1. The piecewise-linear formulation helps in identifying the fluid properties along with several higher temperatures, and CFD computes the values of the properties by linearly interpolating from the defined values. The more data values identified, the accurate the outcome results.

Table 1 Data table of density based on the surrounding temperature.

\begin{tabular}{ccc}
\hline Temperature $\left({ }^{\mathbf{C}} \mathbf{C}\right)$ & Temperature $(\mathbf{K})$ & Density $\left(\mathbf{k g} / \mathbf{m}^{\mathbf{3}}\right)$ \\
\hline-10 & 263.15 & 1.341 \\
-5 & 268.15 & 1.316 \\
0 & 273.15 & 1.292 \\
5 & 278.15 & 1.268 \\
10 & 283.15 & 1.246 \\
15 & 288.15 & 1.225 \\
20 & 293.15 & 1.204 \\
25 & 298.15 & 1.184 \\
30 & 303.15 & 1.164 \\
40 & 313.15 & 1.127 \\
50 & 323.13 & 1.093 \\
60 & 333.13 & 1.06 \\
80 & 353.15 & 1.00 \\
\hline
\end{tabular}

A turbulent type of fluid flow was considered in the simulation due to the nature of the airflow in this scenario. Constant temperature boundary conditions of $60^{\circ} \mathrm{C}$ and $30^{\circ} \mathrm{C}$ were applied on the window with the opposing interior wall fixed at $20^{\circ} \mathrm{C}$. The resulting Grashof numbers for both scenarios were calculated as $1.76 \times 10^{10}$ and $4.41 \times 10^{9}$ respectively, indicative of turbulent flow. The k-omega viscous model was chosen over k-epsilon model in the CFD formulation as it is the k-omega that is recommended for an internal type of analysis for better convergence, unlike the k-epsilon for an exterior simulation [7], [11]. 


\section{RESULTS AND DISCUSSION}

The results presented reveal the potential benefits of smart glazing, as a way of creating a thermally comfortable environment for occupants in an office room. CFD simulations were performed to determine the ambient average temperature of an enclosed room envelope for constant temperature boundary conditions. The ambient temperature and interior air velocity were observed during the simulations. Three different room HVAC system scenarios were developed to examine the performance of the smart window configuration under different temperature conditions. From the presented results, Case A describes the scenario of no ventilation in the room, Case B scenario shows results for passive ventilation and Case $\mathrm{C}$ describes an air conditioning system where cool air flow is used to regulate the room temperature. The obtained results describe the overall differences in the average internal temperature and the air velocity for each case scenario.

\subsection{Thermal and Flow Physics in Office Space}

\section{$\underline{3.1 .1 \text { Constant temperature of } 303.15 \mathrm{~K}\left(30^{\circ} \mathrm{C}\right)}$}

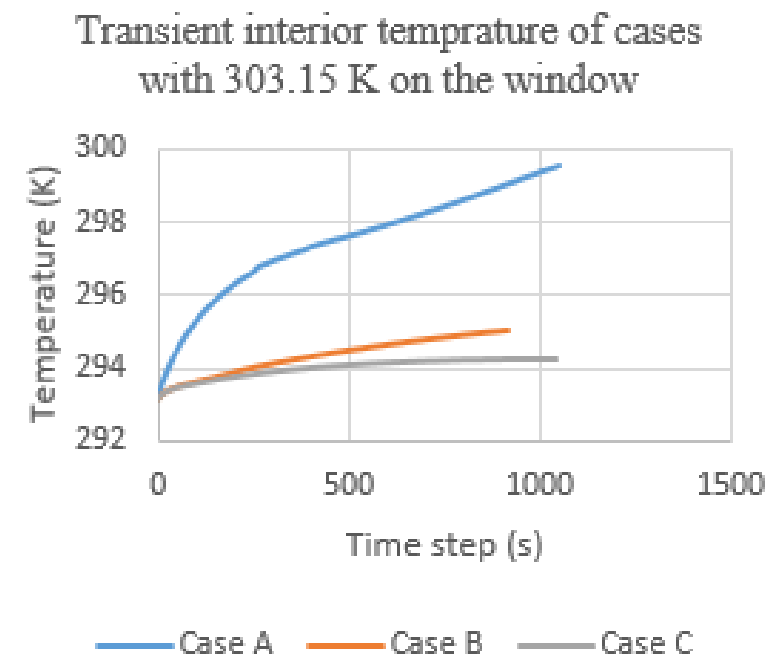

(a)

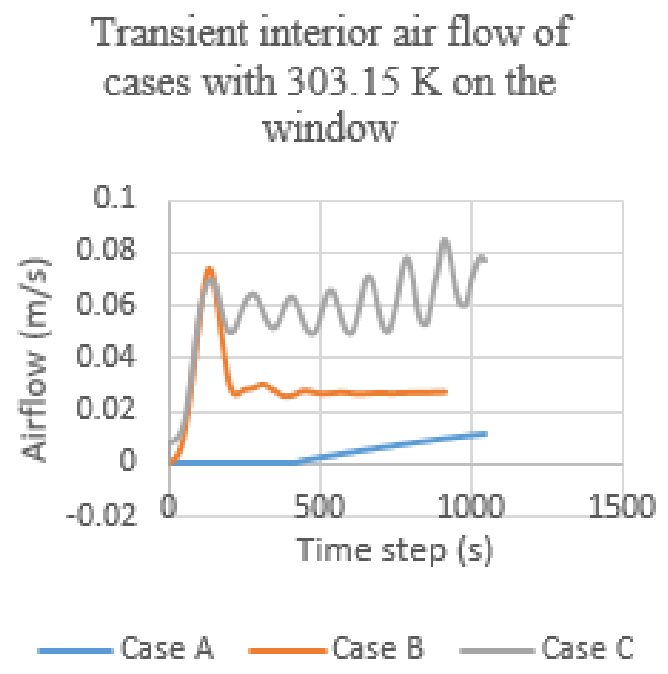

(b)

Fig. 3 Average interior temperature (a) and airflow (b) of all the cases with an exposed temperature of $303.15 \mathrm{~K}\left(30^{\circ} \mathrm{C}\right)$ on the smart window.

The temperature profiles and contours are shown in Fig. 3 and Fig. 4. For the scenario of Case A, the room stays warmer than the scenario of having passive or air conditioning in the room due to lack of air exchange taking place. As shown by the average interior air velocity graph in Fig. 5, the circulation in Case A is lower than in Case B and Case C. The simulations show similarities for each case scenario. The overall temperature values are summarized in Table 2, Table 3 and Table 4. 
TFEC-2020-32102

Following the main objective of the paper to investigate the ability of the smart window to control the transfer of solar energy into a building interior, the study of the two ventilated cases may have expected to yield results for the interior temperature and the air circulation closer to more ideal occupant thermal comfort temperatures. In case B the smart glazing sustains an appropriate temperature with passive ventilation and for a moderate level of solar radiation. However, it was observed that there was an increase in the average interior temperature compared to the recommended room temperature of $23^{\circ} \mathrm{C}$ for case B with a temperature of $26^{\circ} \mathrm{C}$ observed after 1000 seconds for the case.
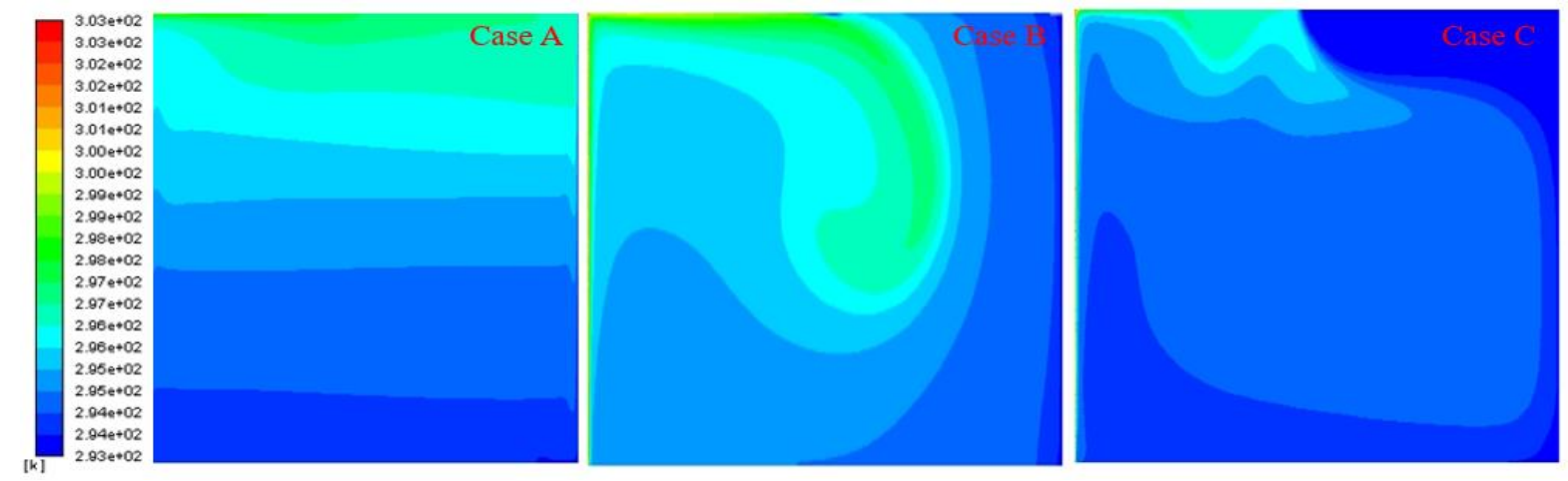

Fig. 4 Description of an average interior temperature distribution of the three cases with a constant temperature of $303.15 \mathrm{~K}\left(30^{\circ} \mathrm{C}\right)$ exposed on the smart window.
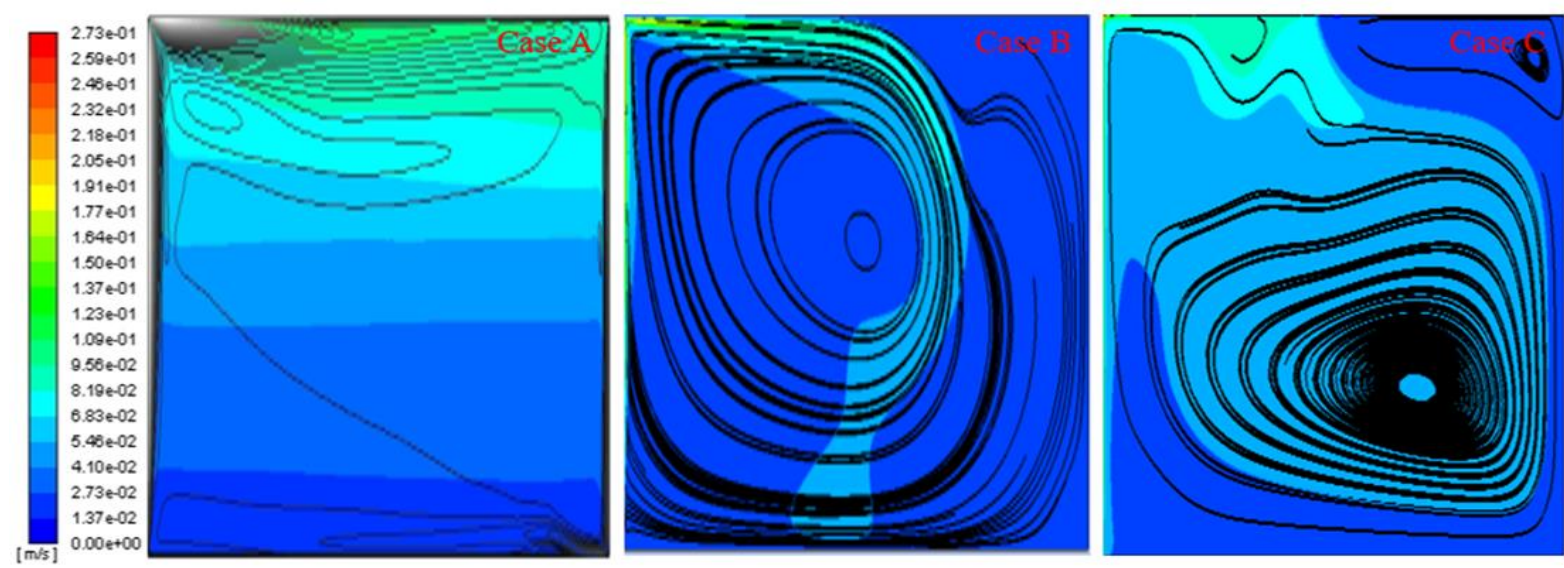

Fig. 5 Evaluation of the average interior air velocity in the room of the cases as a constant temperature of $303.15 \mathrm{~K}\left(30^{\circ} \mathrm{C}\right)$ was exposed on the smart window. 


\subsubsection{Constant temperature of $333.15 \mathrm{~K}\left(60^{\circ} \mathrm{C}\right)$}

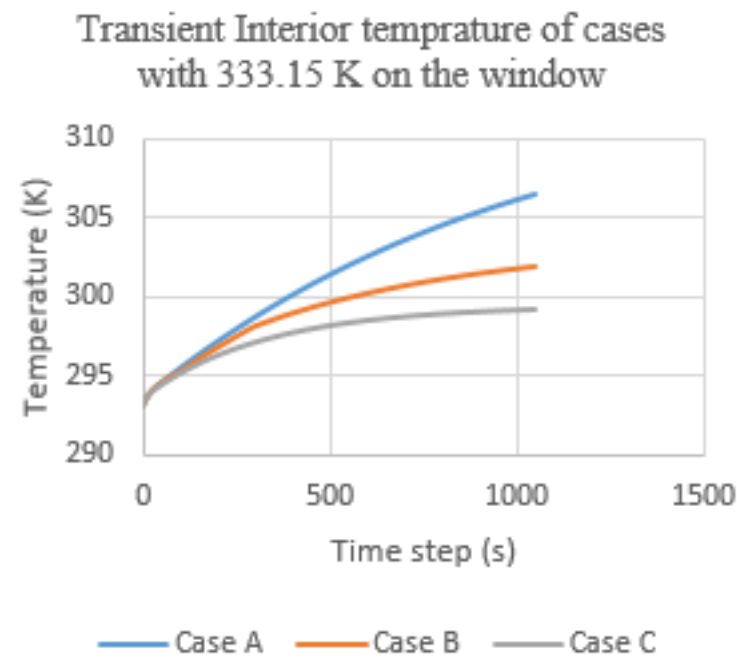

(a)

\section{Transient Interior air flow of cases with $333.15 \mathrm{~K}$ on the window}

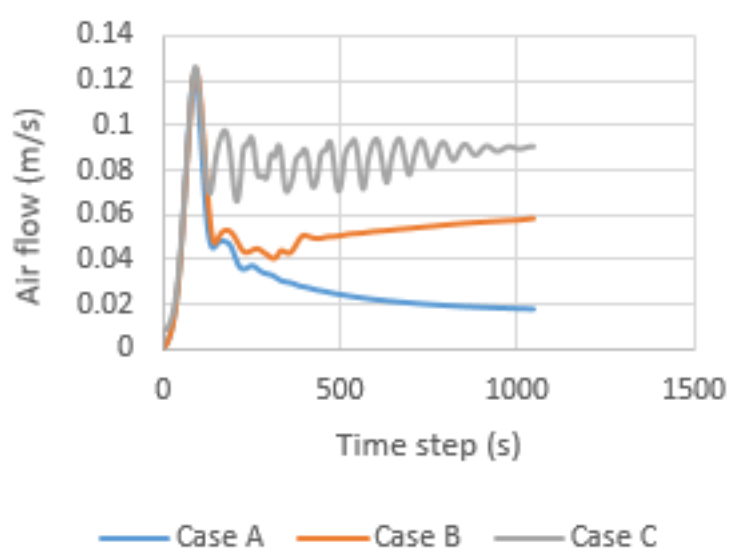

(b)

Fig. 6 Average interior temperature (a) and airflow (b) of all the cases with an exposed temperature of $333.15 \mathrm{~K}\left(60^{\circ} \mathrm{C}\right)$ on the smart window.

The results are presented for the second set of cases relative to a temperature boundary condition imposed on the smart window. Fig. 7 demonstrates the results of the simulation when the window was exposed to a constant temperature of $333.15 \mathrm{~K}\left(60^{\circ} \mathrm{C}\right)$. It shows a more pronounced interior temperature distribution with higher temperatures on the top and lower temperatures on the bottom in all the cases than when the window was exposed to a constant temperature of $303.15 \mathrm{~K}\left(30^{\circ}\right)$. In terms of the interior air velocity, depending on the conditions for each setting case, interior air velocity tends to increase in the initial stage of the transient simulation until it reaches a steady-state condition as presented in the plots of Fig. 3 and Fig. 6 and the visual image in Fig. 5 and Fig. 8. The results presented indicate that air conditioning is required for an intense level of solar radiation corresponding to a window temperature of $60^{\circ} \mathrm{C}$ to maintain appropriate thermal comfort levels. The temperature boundary condition of $60^{\circ} \mathrm{C}$ is an extreme scenario, with interior temperatures of $26^{\circ} \mathrm{C}$ observed in Case $\mathrm{C}$ even with air conditioning.
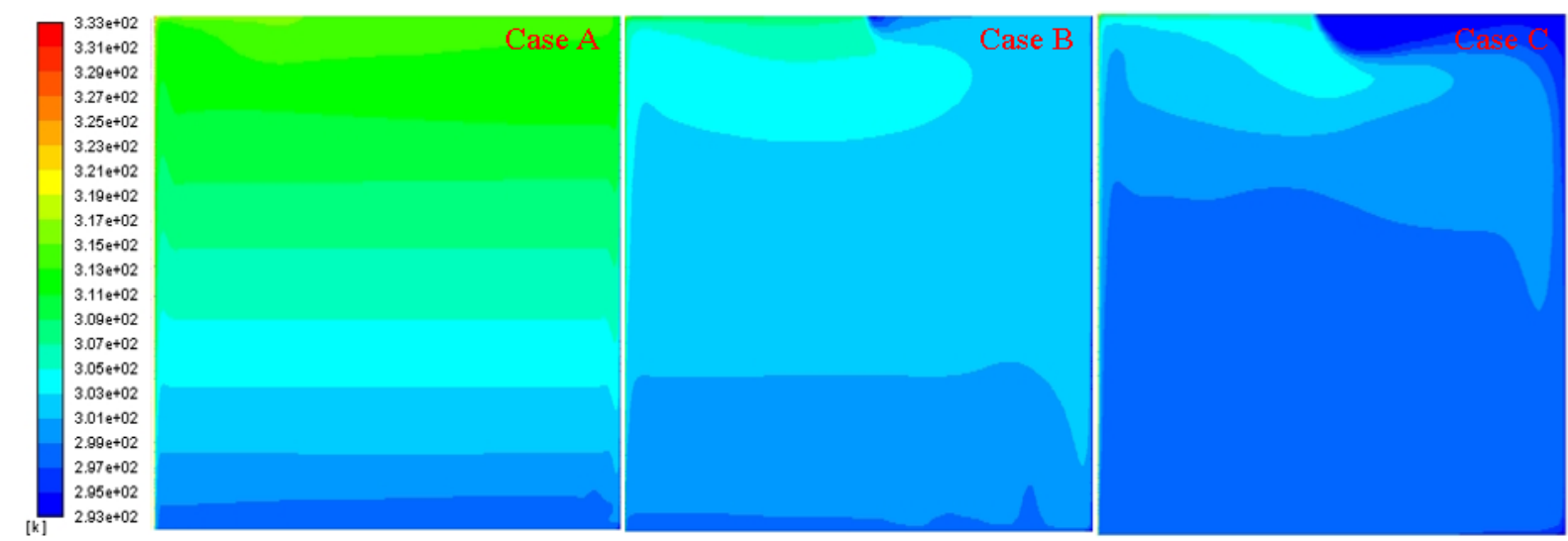

Fig. 7 Description of an average interior temperature distribution of the three cases with a constant temperature of $333.15 \mathrm{~K}\left(60^{\circ} \mathrm{C}\right)$ exposed on the smart window. 

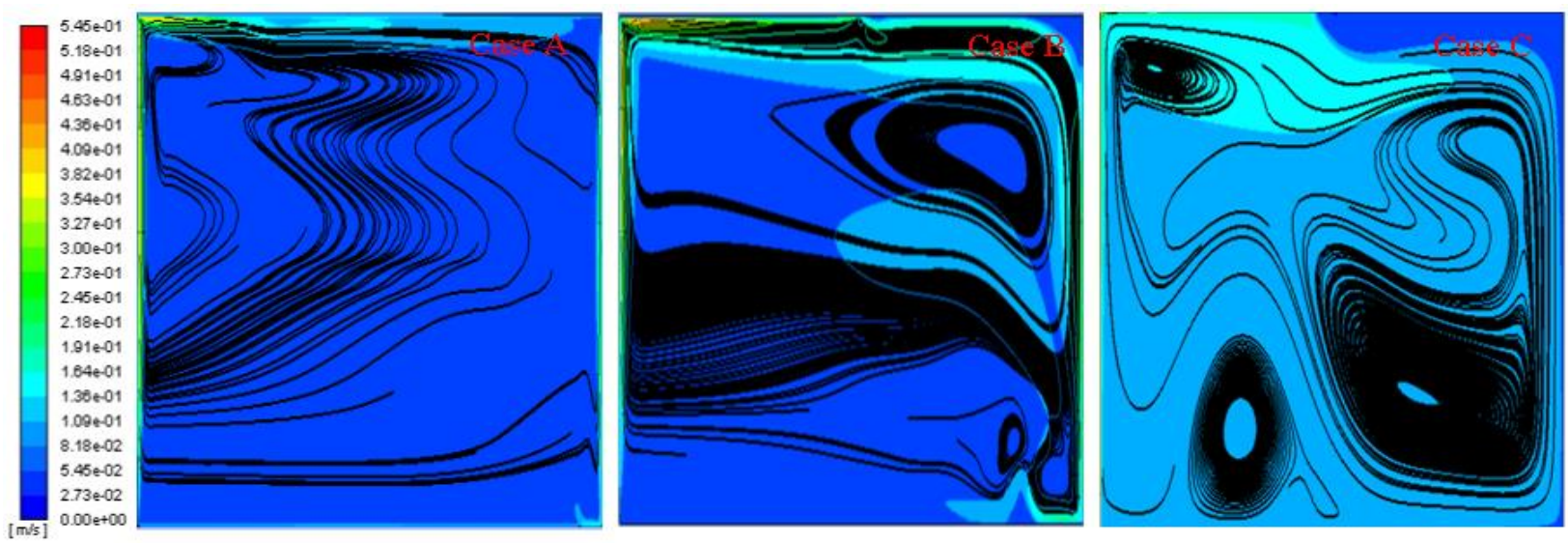

Fig. 8 Evaluation of the average interior airflow in the room of the cases as a constant temperature of $333.15 \mathrm{~K}\left(60^{\circ} \mathrm{C}\right)$ was exposed on the smart window.

Table 2 Average temperature of the room envelope when the window was exposed to a constant temperature of $333.15 \mathrm{~K}$ for Case $\mathrm{A}$ (no ventilation).

\begin{tabular}{ccc}
\hline $\begin{array}{c}\text { Boundary } \\
\text { condition }\end{array}$ & Temperature $(\mathrm{K})$ & Temperature $\left({ }^{\circ} \mathrm{C}\right)$ \\
\hline Front & 293.15 & 20.00 \\
Window & 333.15 & 60.00 \\
Floor & 298.55 & 25.41 \\
Roof & 315.29 & 42.15 \\
Interior & 306.49 & 33.35
\end{tabular}

Table 3 Average temperature room envelope when the window was exposed to a constant temperature of $333.15 \mathrm{~K}$ for Case $\mathrm{B}$ (passive ventilation).

\begin{tabular}{ccc}
\hline $\begin{array}{c}\text { Boundary } \\
\text { condition }\end{array}$ & Temperature $(\mathrm{K})$ & Temperature $\left({ }^{\circ} \mathrm{C}\right)$ \\
\hline Front & 293.15 & 20.00 \\
Window & 333.15 & 60.00 \\
Floor & 298.75 & 25.60 \\
Roof & 306.49 & 33.34 \\
Interior & 301.97 & 28.82 \\
Inlet & 304.67 & 31.52 \\
\hline
\end{tabular}

Table 4 Average temperature of the room envelope when the window was exposed to a constant temperature of $333.15 \mathrm{~K}$ for Case $\mathrm{C}$ (air conditioning).

\begin{tabular}{ccc}
\hline $\begin{array}{c}\text { Boundary } \\
\text { condition }\end{array}$ & Temperature $(\mathrm{K})$ & Temperature $\left({ }^{\circ} \mathrm{C}\right)$ \\
\hline Front & 293.15 & 20.00 \\
Window & 333.15 & 60.00 \\
Floor & 297.30 & 24.15 \\
Roof & 301.92 & 28.77 \\
Interior & 299.12 & 25.97 \\
Inlet & 293.15 & 20.00 \\
\hline
\end{tabular}


The study [5] on the evaluation of thermal comfort in naturally ventilated school classrooms using CFD carried similar natural convection behaviour to the observations in the present study. However, their study was based on a normal glass window, and the study focused on the opening of the window and the effect it has on the occupants. Table 3 describes the average temperature values of the room envelope when the temperature boundary condition applied to the window was at a value of $333.15 \mathrm{~K}$. Table 2, 3 and 4 summarize the average temperature values of the room envelope when the window was exposed to a constant temperature of $303.15 \mathrm{~K}$ and $333.15 \mathrm{~K}$. The interior temperature tends to have differences according to the cases as expected with temperature drops present with the introduction of an air conditioning system. The next part of this study would introduce transient temperature and heat flux boundary conditions on the windows which represent the response of the smart windows over longer periods of time.

\section{CONCLUSIONS AND RECOMMENDATION}

Smart glazing coupled with passive ventilation for moderate and high levels of solar radiation offer an adequate solution to thermal comfort in the office space analyzed. For extreme cases of solar radiation and high glazing temperatures, air conditioning may be required to maintain thermal comfort of occupants. The methodology in the current study utilized constant temperature conditions on the window. It would be very interesting to consider a transient temperature change over time on the window since the temperature does not stay constant in reality. The results presented offer a benchmark for future simulations where the thermal and fluid behavior are consistent with literature of similar research which also indicate smart window systems have a very substantial benefit of not just solving the overheating of a room by blocking the transmission of heat; but also controlling the amount of energy that is consumed in a room. Further work is to perform the research using a 3D simulation of a room with a transient temperature and heat flux exposed on the smart window to obtain a clear understanding of how the smart window functions in preventing the overheating of a room. This would draw a wider depiction of the benefit of the smart windows.

\section{NOMENCLATURE}

$\begin{array}{lll}\mathrm{T} & \text { Temperature } & \mathrm{K} \text { or }{ }^{\circ} \mathrm{C} \\ \mathrm{V} & \text { velocity } & \mathrm{m} / \mathrm{s} \\ \mathrm{Q} & \text { Heat flux } & \mathrm{W} / \mathrm{m}^{2} \\ \varepsilon & \text { black body emissivity } & -\end{array}$

\section{ACKNOWLEDGMENT}

This research was supported by the President Fellowship program at the Institute of Technology Carlow Ireland. I offer my gratitude to all the supporting team for their guidance, enthusiastic encouragement, and useful critiques on this research project. 


\section{REFERENCES}

[1] R. Crahmaliuc, Thermal Comfort in Buildings: How to Better Control and Predict, SimScale. (2016). https://www.simscale.com/blog/2016/08/thermal-comfort-in-buildings/ (accessed December 18, 2019).

[2] M. Hajdukiewicz, M. Geron, M.M. Keane, Calibrated CFD simulation to evaluate thermal comfort in a highly-glazed naturally ventilated room, Build. Environ. 70 (2013) 73-89. https://doi.org/10.1016/j.buildenv.2013.08.020.

[3] Y. Ajaji, P. André, Thermal Comfort and Visual Comfort in an Office Building Equipped with Smart Electrochromic Glazing: An Experimental Study, Energy Procedia. 78 (2015) 2464-2469. https://doi.org/10.1016/j.egypro.2015.11.230.

[4] A. Ghosh, B. Norton, A. Duffy, Behaviour of a SPD switchable glazing in an outdoor test cell with heat removal under varying weather conditions, Appl. Energy. 180 (2016) 695-706. https://doi.org/10.1016/j.apenergy.2016.08.029.

[5] C. Angelopoulos, M. Cook, C. Iddon, S. Porritt, Evaluation of thermal comfort in naturally ventilated school classrooms using CFD, 2017.

[6] C. Buratti, D. Palladino, E. Moretti, Prediction Of Indoor Conditions And Thermal Comfort Using CFD Simulations: A Case Study Based On Experimental Data, Energy Procedia. 126 (2017) 115122. https://doi.org/10.1016/j.egypro.2017.08.130.

[7] K. Javad, G. Navid, Thermal comfort investigation of stratified indoor environment in displacement ventilation: Climate-adaptive building with smart windows, Sustain. Cities Soc. 46 (2019) 101354. https://doi.org/10.1016/j.scs.2018.11.029.

[8] M. Sabry, P.C. Eames, H. Singh, Y. Wu, Smart windows: Thermal modelling and evaluation, Sol. Energy. 103 (2014) 200-209. https://doi.org/10.1016/j.solener.2014.02.016.

[9] T. Zitzmann, Adaptive modelling of dynamic conjugate heat transfer and air movement using computational fluid dynamics, De Montfort University, Leicester, UK, 2007.

[10]D. Prakash, P. Ravikumar, Analysis of thermal comfort and indoor air flow characteristics for a residential building room under generalized window opening position at the adjacent walls, Int. J. Sustain. Built Environ. 4 (2015) 42-57. https://doi.org/10.1016/j.ijsbe.2015.02.003.

[11]W. Frei, Which Turbulence Model Should I Choose for My CFD Application?, COMSOL Multiphysics. (2017). https://www.comsol.com/blogs/which-turbulence-model-should-choosecfd-application/ (accessed December 18, 2019). 